\title{
Forensic study on the effect of age and illness (Parkinsonism) on handwriting characteristics
}

\author{
Komal Saini ${ }^{*}$ and Manpreet Kaur
}

\begin{abstract}
Background: Handwriting is a neuromuscular task. Old age and illness may produce significant deteriorating effects on the quality of handwriting/signatures of an individual. In some cases, the affected writings may be suspected of being forged due to poor line quality of handwriting. Important documents such as wills, receipts, agreements, contracts, notes, and drafts involve handwritten contents that are often questioned to prove their identity and genuineness. The document examiners may face difficulty to get an adequate number of contemporary standard samples while handling questioned handwriting samples of old age persons and Parkinsonism patients. Therefore, we conducted a qualitative and statistical study to analyze the changes in various handwriting features due to old age and Parkinsonism.
\end{abstract}

Methodology: Handwriting samples from 50 healthy old age persons and 25 individuals suffering from Parkinsonism were collected with their consent. Handwriting features such as line quality defects (tremors, retouchings, and pen lifts), letter formations, abbreviation/simplification of letters or their parts, nature of initial and terminal strokes, nature of connecting strokes, writing speed, overall size, and alignment were analyzed qualitatively and statistically through paired $t$ test using SPSS software.

Results: According to results, marked variations were evident in most of the handwriting features in case of old age persons and in case of individuals suffering from Parkinsonism. Two features, namely retouchings and alignment, were least affected in the handwritings of patients suffering from Parkinsonism.

Conclusion: According to the results of this study, old age and illness affect the handwriting of an individual in a considerable manner. Marked deterioration in the quality of handwriting/signatures can be observed in case of old age persons and in individuals suffering from Parkinsonism, which makes their writing appear different altogether as compared to their corresponding normal writing. The document examiner must be aware of this fact while examining such cases.

Keywords: Handwriting, Old age, Parkinsonism, Questioned documents, Document examiners

\section{Background}

Handwriting results from the neuromuscular coordination of the human body. Old age and neurological illness (such as Parkinsonism) affect the neurological and muscular system of the body. These factors thus produce significant effects on the handwriting of an individual (Huber and Headrick 1999), which can range from minor variations to a marked decline in the writing skill, muscular coordination, speed, deterioration of

\footnotetext{
*Correspondence: komal2saini@yahoo.com

Department of Forensic Science, Punjabi University, Patiala, Punjab, India
}

letter formations, and so on. Some of the changes in handwriting that are caused due to old age and illness resemble few characteristics of forgery, which can be considered as non genuine, if overlooked. In such cases, document experts are required to be acquainted with detailed knowledge of the effects of old age and Parkinsonism on handwriting.

Previous studies have demonstrated that old age and illness affect the handwriting of an individual drastically (Boisseau et al. 1986; Harralson 2013; Hilton 1956, 1977; Sulner 1966; Komal 2015; Rosenblum et al. 2013; 
Walton 1997). Many researchers have also conducted kinematic studies on the effects of old age and Parkinsonism on handwriting of individuals (Drempt et al. 2011; Caligiuri et al. 2014; Gemmert et al. 1999, 2001; Gemmert et al. 2003; Inzelberg et al. 2016; Kim et al. 2004; Nackaerts et al. 2017; Rosenblum and Werner 2006; Rosenblum et al. 2013).

The present research has been conducted with an aim to study the effects of old age and Parkinsonism on handwriting characteristics with a particular emphasis on qualitative and statistical analysis of handwriting samples.

\section{Materials and methods \\ Ethical approval}

We obtained approval to collect handwriting/signature samples from old age persons and from individuals suffering from Parkinsonism by the Institutional Ethical Committee.

\section{Collection of samples}

Handwriting samples were collected from 50 old age persons. Individuals who were 60 years or above and those who were not suffering from any serious ailment were included in this study. Handwriting samples from 25 individuals suffering from Parkinsonism were collected by visiting various neurology and physiotherapy centers under the supervision of doctors. Information such as age, gender, educational qualification, and occupation was obtained from each subject. The background details of old age and Parkinsonism subjects have been given in Table 1.

In order to study the effect of old age and Parkinsonism, handwriting samples of both groups (old age and Parkinsonism) were collected in two conditions, that is, before (pre-) and after (post-) the onset of old age and Parkinsonism. These two conditions were taken as two variables, that is, "Bf" and "Af," where "Bf" and "Af" denoted handwriting samples obtained from subjects before and after the onset of old age and Parkinsonism respectively.

Handwriting samples in "Bf" condition were collected by requesting the subjects to provide handwriting/signature samples from their previous records. These samples were considered as "control samples" for the present study. The same subjects were then requested to write the same matter again in order to collect handwriting samples in "Af" condition.

\section{Analysis}

Handwriting samples executed in both conditions, that is "Bf" and "Af," were qualitatively analyzed and compared interse with regard to handwriting characteristics, such as line quality (tremor, retouching, pen lifts), letter formation, abbreviation/simplification of letters/parts, initial and terminal strokes, speed, connecting strokes, overall size, and alignment.
Table 1 Background details of old age and Parkinsonism subjects

\begin{tabular}{|c|c|c|c|}
\hline Parameters & Category & Count & \%age \\
\hline \multicolumn{4}{|l|}{ Old age subjects } \\
\hline \multirow[t]{3}{*}{ Age } & $60-70$ & 12 & $24 \%$ \\
\hline & $71-80$ & 18 & $36 \%$ \\
\hline & $81-90$ & 20 & $40 \%$ \\
\hline \multirow[t]{2}{*}{ Gender } & Male & 40 & $80 \%$ \\
\hline & Female & 10 & $20 \%$ \\
\hline \multirow[t]{2}{*}{$\begin{array}{l}\text { Educational } \\
\text { qualification }\end{array}$} & $\begin{array}{l}\text { Below matric-senior } \\
\text { secondary }\end{array}$ & 32 & $64 \%$ \\
\hline & Graduation-post graduation & 18 & $36 \%$ \\
\hline \multirow[t]{2}{*}{ Occupation } & Self-employed & 11 & $22 \%$ \\
\hline & Job employee & 39 & $78 \%$ \\
\hline \multicolumn{4}{|c|}{ Parkinsonism subjects } \\
\hline \multirow[t]{4}{*}{ Age } & $50-60$ & 2 & $8 \%$ \\
\hline & $61-70$ & 7 & $28 \%$ \\
\hline & $71-80$ & 7 & $28 \%$ \\
\hline & $81-90$ & 9 & $36 \%$ \\
\hline \multirow[t]{2}{*}{ Gender } & Male & 16 & $64 \%$ \\
\hline & Female & 9 & $36 \%$ \\
\hline \multirow[t]{2}{*}{$\begin{array}{l}\text { Educational } \\
\text { qualification }\end{array}$} & $\begin{array}{l}\text { Below matric-senior } \\
\text { secondary }\end{array}$ & 12 & $48 \%$ \\
\hline & Graduation-post graduation & 13 & $52 \%$ \\
\hline \multirow[t]{2}{*}{ Occupation } & Self-employed & 14 & $56 \%$ \\
\hline & Job employee & 11 & $44 \%$ \\
\hline
\end{tabular}

Table 1 shows details of all the subjects of old age and Parkinsonism, showing parameters, their categorization, number of subjects who belonged to a particular category

The handwriting characteristics were examined and coded as in Table 2. The observed data was analyzed statistically through paired $t$ test using SPSS software in order to perform interse comparison of "Bf" and "Af".

Null hypothesis held that there would be no overall difference in handwriting characteristics in handwriting samples of persons before and after the onset of old age and illness (Parkinsonism). Thus, if the null hypothesis would be true:

$$
\mathrm{H}_{0}: \mu_{1}=\mu_{2}
$$

Alternate hypothesis would be:

$$
\mathrm{H}_{1}: \mu_{1} \neq \mu_{2}
$$

Where $\mathrm{H}_{0}$ represents null hypothesis, $\mathrm{H}_{1}$ represents alternate hypothesis, $\mu_{1}$ is the mean of population of variable "Bf," and $\mu_{2}$ is the population mean of variable "Af." Alternate hypothesis stated that there would be significant difference between the means of paired populations, that is, old age and Parkinsonism would have 
Table 2 Coding and categorization of handwriting characteristics along variables observed during analysis

\begin{tabular}{|c|c|c|c|c|c|}
\hline \multirow{2}{*}{$\begin{array}{l}\text { S. } \\
\text { No. }\end{array}$} & \multirow[t]{2}{*}{ Handwriting characteristics } & \multirow[t]{2}{*}{ Coding } & \multirow{2}{*}{$\begin{array}{l}\text { Coding } \\
\text { along } \\
\text { variables }\end{array}$} & \multicolumn{2}{|l|}{ Categorization of characteristics } \\
\hline & & & & Category 1 (0) & Category 2 (1) \\
\hline 1. & Line quality & & & & \\
\hline 1.1 & Tremor & T & T_Bf/T_Af & $0=$ Absent & $1=$ Present \\
\hline 1.2 & Retouching & Rt & Rt_Bf/Rt_Af & $0=$ Absent & $1=$ Present/Increase \\
\hline 1.3 & Pen lifts & PL & PL_Bf/PL_Af & $0=$ Absent & $1=$ Present/Increase \\
\hline 2. & Letter formation & LF & LF_Bf/LF_Af & $0=$ Deterioration Absent & $1=$ Deterioration Present \\
\hline 3. & $\begin{array}{l}\text { Abbreviation/simplification of letters/ } \\
\text { parts }\end{array}$ & AS & $\begin{array}{l}\text { AS_Bf/ } \\
\text { AS_Af }\end{array}$ & $0=$ Absent & $1=$ Present \\
\hline 4. & Initial and terminal strokes & $\ln T$ & $\begin{array}{l}\text { InT_Bf/ } \\
\text { InT_Af }\end{array}$ & $0=$ Tapered and smooth & $1=$ Tremulous and blunt \\
\hline 5. & Connecting strokes & CS & $\begin{array}{l}\text { CS_Bf/ } \\
\text { CS_Af }\end{array}$ & $0=$ Normal and smooth & 1 = Defective \\
\hline 6. & Speed & S & S_Bf/S_Af & $0=$ Rapid & $1=$ Decline \\
\hline 7. & Overall size & OS & $\begin{array}{l}\text { OS_Bf/ } \\
\text { OS_Af }\end{array}$ & $0=$ Constant & $\begin{array}{l}1=\text { Change (increase/ } \\
\text { decrease) }\end{array}$ \\
\hline 8. & Alignment & Al & Al_Bf/Al_Af & $\begin{array}{l}0=\mathrm{H} / \mathrm{Uh} / \mathrm{Dh} / \mathrm{Mi} \text { (combination of any of } \mathrm{H}, \mathrm{Uh} \text {, } \\
\text { and } \mathrm{Dh} \text { ) }\end{array}$ & $1=$ Change in alignment \\
\hline \multicolumn{6}{|c|}{ Variables selected } \\
\hline \multicolumn{2}{|r|}{$\begin{array}{l}\text { 1. Pre-condition (before onset of old age } \\
\text { and Parkinsonism) }\end{array}$} & Bf & & & \\
\hline \multicolumn{2}{|r|}{$\begin{array}{l}\text { 2. Post-condition (after onset of old age } \\
\text { and Parkinsonism) }\end{array}$} & Af & & & \\
\hline
\end{tabular}

Table 2 shows coding of handwriting characteristics and variables selected for the study, coding of characteristics and variables together, and categorization of handwriting characteristics for statistical analysis

significant effect on the handwriting characteristics of individuals.

Scientifically accepted level of significance in research, that is, 0.05 was chosen. If significance (two-tailed) value, $p$ value, was found to be less than $0.05(p<0.05)$, it would reject the null hypothesis. This means that old age and illness have significant effect on the handwriting characteristics in handwritings of affected individuals.

\section{Results}

The results were given as:

Qualitative analysis

Statistical analysis

\section{Qualitative analysis}

Following observations were made during the analysis of handwriting samples of old age and Parkinsonism:

\section{Line quality defects}

Tremor Tremor was observed in 39 out of 50 writing samples of old age persons, which showed variations in the form of slight changes in writing impulses up to marked deteriorations to the level of illegibility. Tremor in the form of peculiar zigzag type of strokes (Fig. 1a) and bunches was observed on the strokes of a few letters. Few samples showed lesser tremors and better muscular coordination in some signatures. Increased tremor has been observed in 19 out of a total 25 handwriting samples of individuals suffering from Parkinsonism. These samples revealed tremor in the form of typical wavy strokes in almost all writings as if the subjects had written by keeping the paper on a wavy surface (Fig. 1b).

Retouchings Retouchings were identified in the form of extra strokes and bold overwriting in 17 out of 50 handwriting samples of old age persons. At some places, even the same strokes were doubled/overwritten to make them look more legible. Such features were not present in the earlier writings of these individuals. In the case of individuals suffering from Parkinsonism, retouchings were not found to be common in their writings. However, only four samples were found to exhibit retouching in increased number as compared to their old handwritings.

Pen lifts Pen lifts were identified in 35 out of 50 handwriting samples of old age persons. Increase in the number of pen lifts resulted in the lack of proper connections between letters, continuity of strokes, and formation of parts of letters (Fig. 2a). Handwriting samples of 15 

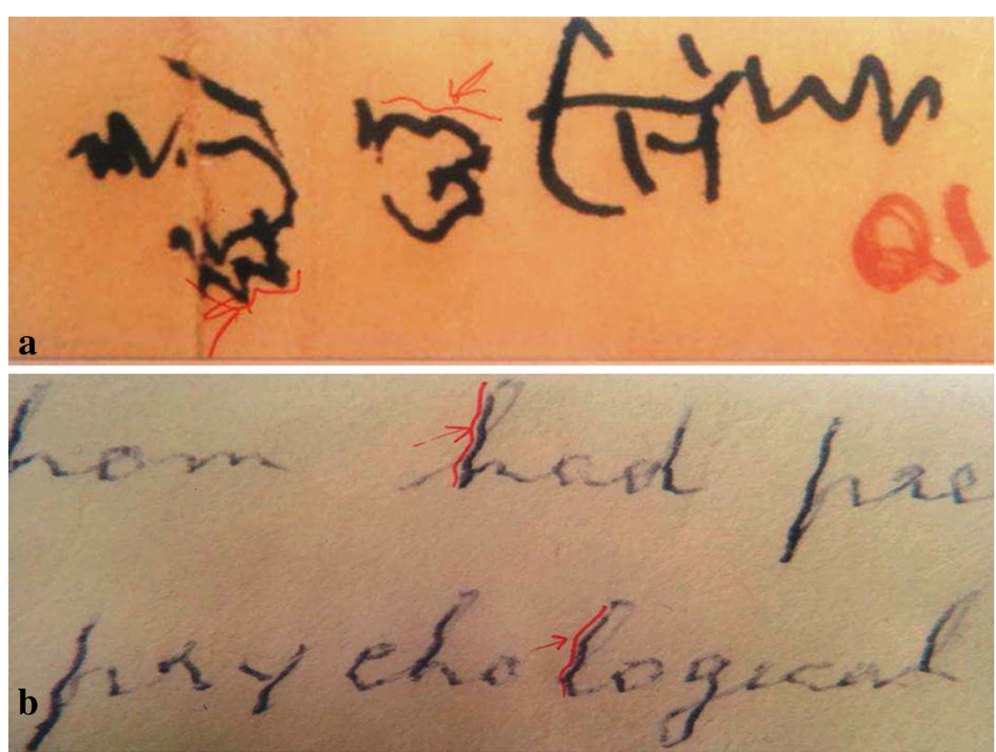

Fig. 1 Tremors. a Signature sample of old aged subject showing peculiar zigzag type of tremor. b Typical wavy strokes in the handwriting sample of Parkinsonism patient

individuals showed high increase in number of pen lifts (Fig. 2b). However, remaining ten handwriting samples showed lesser number of pen lifts than that of their corresponding earlier written records.

\section{Letter formation}

Change in letter formations was observed in 30 out of 50 handwriting samples of old age persons. In 12 samples, whole signatures or maximum parts of signatures were found to be illegible. In case of two samples, formation of letters was found to be more angular as compared to their earlier writings. Only slight change in letter formations was observed in 16 samples. Deterioration of letters/words was observed in 18 handwriting samples of individuals suffering from Parkinsonism. Missing characters of some letters or abbreviation of some letters or their parts were also found.
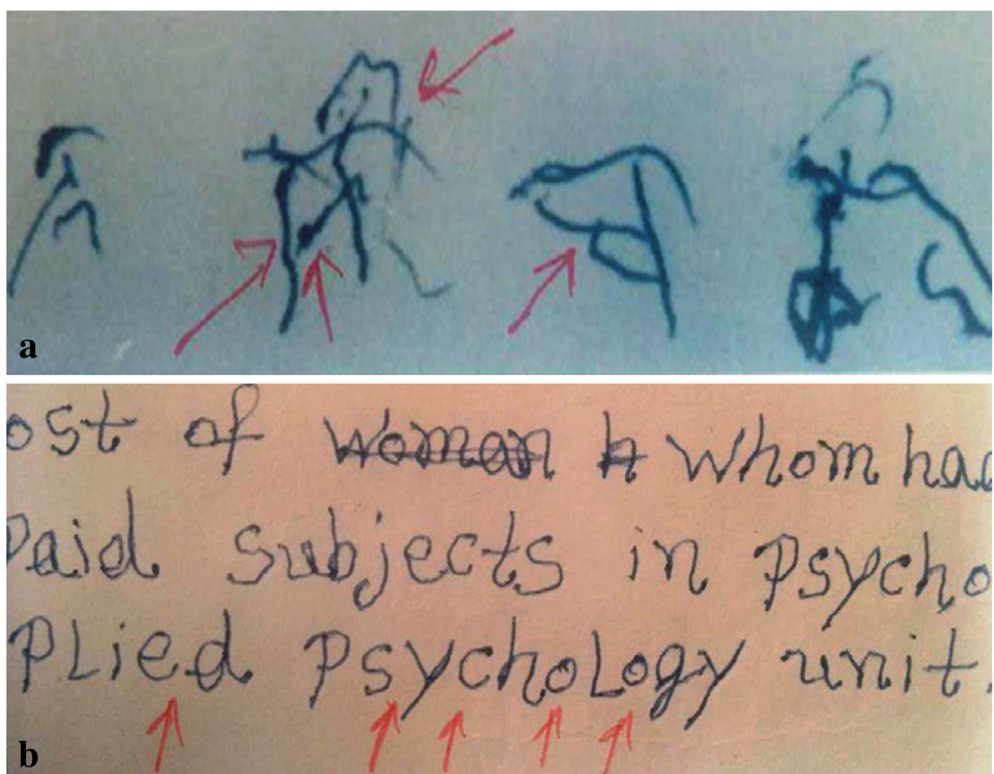

Fig. 2 Pen lifts. a Signature executed in old age showing pen lifts before writing each letter. b Handwriting sample of Parkinsonism patient showing most of the letters written separately 


\section{Abbreviation/simplification of letters or their parts}

Abbreviation/simplification of letters was observed in the form of few curves or strokes and omission of letters, their parts, or diacritic marks in 32 handwriting samples of old age persons. Of them, 11 samples, showed the omission of letters or diacritic marks (Fig. 3(a)). Furthermore, 21 samples showed simplification/abbreviation of letters or diacritic marks. In all writing samples of individuals suffering from Parkinsonism, it was found that the writers simplified/abbreviated letters at one or other place. In the case of signature samples, there was the tendency to simplify the terminal portions, or and in some cases, the terminal letters were missing (Fig. 3(b)). Seven samples showed comparatively less simplifications

\section{Nature of initial and terminal strokes}

In case of 14 out of 50 handwriting samples of old age subjects, the presence of extra strokes, blunt clubshaped start, and even wedge-shaped strokes was observed on initial strokes (Fig. 4a). Most of the writings also showed the tendency of the writers to abbreviate letters or formation of letters in an illdefined manner at terminal portions. Earlier writings of these writers did not reveal these features. In the case of 22 handwriting samples of individuals suffering from Parkinsonism, the presence of heavy writing pressure, extra strokes, and even comparatively more tremors was observed (Fig. 4b). Similar features were observed at terminal portions.

\section{Nature of connecting strokes}

In the case of 14 handwriting samples of old age persons, marked changes were identified in the connection between letters as indicated by tremulous and ill-defined strokes. The connecting strokes showed overlappings, overwriting, and pen lifts at some places (Fig. 4c). Twelve samples showed comparatively less degree of tremor, and connecting strokes revealed a smaller number of pen lifts. Ill-defined and deteriorated connections in the letters were observed in 21 out of 25 handwriting samples of individuals suffering from Parkinsonism. Tremulous and shaky strokes were observed along with pen lifts, extra strokes, and pen pauses (Fig. 4d). The remaining four samples showed placing of comparatively less tremors, pen lifts, and awkward movements on connecting strokes at some places.

\section{Writing speed}

In 39 out of 50 handwriting samples of old age persons, we observed a decline in the writing speed as compared to their earlier writings as indicated by tremulous and ill-defined strokes, showing the very slow speed of writing (Fig. 5(a)). In 19 out of 25 handwriting samples of individuals suffering from Parkinsonism, there was a marked decline in the speed of writing. Even the writers took 1 to $2 \mathrm{~min}$ to write a few letters or signatures (Fig. 5(b)). Comparatively less change in the writing speed was observed in the remaining six samples.

\section{Overall size}

An overall increase in the size of writings was observed in 18 samples of old age persons. Of them, three samples also showed double-sized letters (Fig. 6(a)). In the case of six signature samples, size of letters of the same writer was found to be inconsistent. These were not found in the earlier writings of these individuals. A decrease in overall size of the handwritings was observed in 21 samples of individuals suffering from Parkinsonism (Fig. 6(b)). Though, two handwritings showed increase in size and two subjects' writings also remained constant out of 25 subjects.

\section{Alignment}

Alignment was not much affected in the writings of old age persons as it was observed to show variations in only
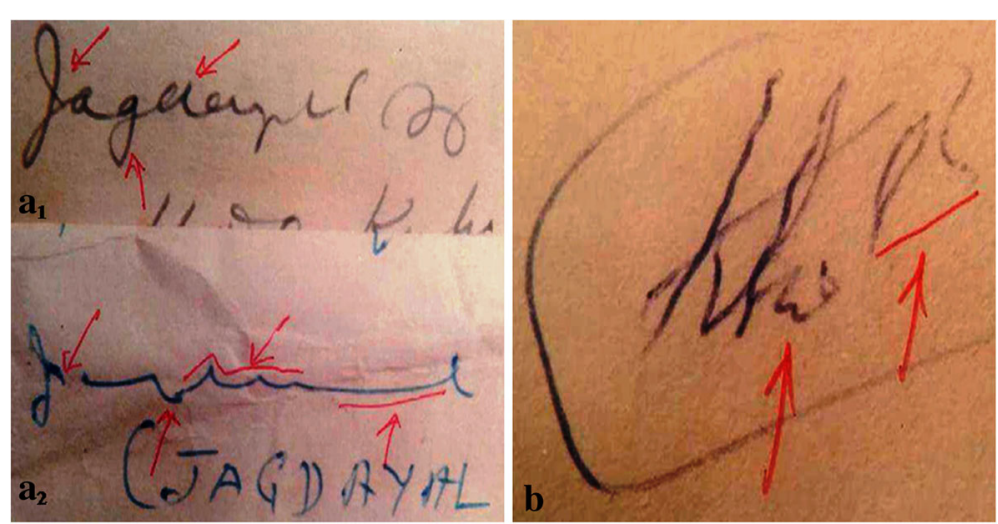

Fig. 3 Simplification/abbreviation. $\left(\mathrm{a}_{1}\right)$ Signature sample executed before the age of 60 years of a subject. $\left(\mathrm{a}_{2}\right)$ Signature sample showing simplification of letters as compared to old signature $\left(a_{1}\right)$. (b) Signatures of a Parkinsonism patient showing abbreviations and simplifications of letters 

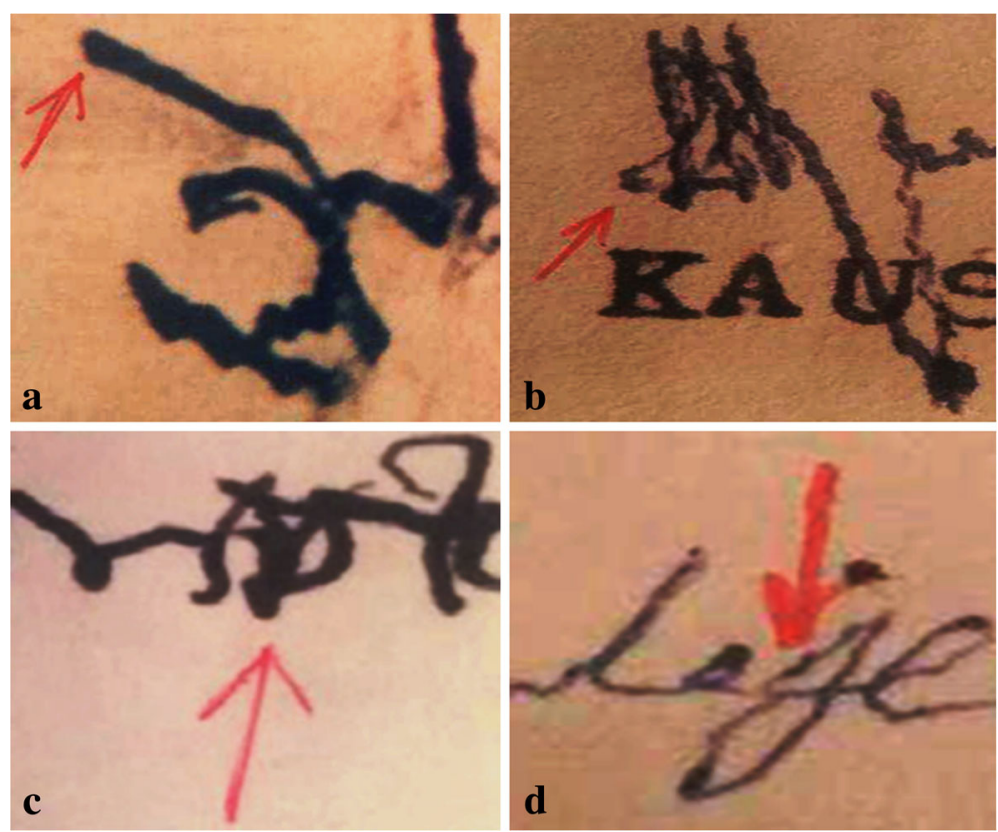

Fig. 4 Initial, terminal, and connecting strokes. a Signatures of an aged subject showing peculiar wedge shaped initial strokes. b Signatures of a Parkinsonism patient revealing difficulty in the starting of strokes. c Signatures of an aged person showing overlapping strokes and overwriting at place of connecting strokes. $\mathbf{d}$ Handwriting sample of Parkinsonism patient showing tremulous and shaky connecting strokes

five out of 50 samples. Similar variations were observed in the earlier writings of these individuals. No significant change was observed in the alignment of writings collected from individuals suffering from Parkinsonism. Only four out of 25 handwriting samples showed change in alignment of handwriting due to effect of Parkinsonism.

\section{Statistical analysis}

Detailed statistical results of paired $t$ test of both groups, old age and Parkinsonism subjects, have been given in Tables 3 and 4 respectively, which shows two-tailed significance values ( $p$ values) obtained after comparison of mean values of "Bf" and "Af" variables.
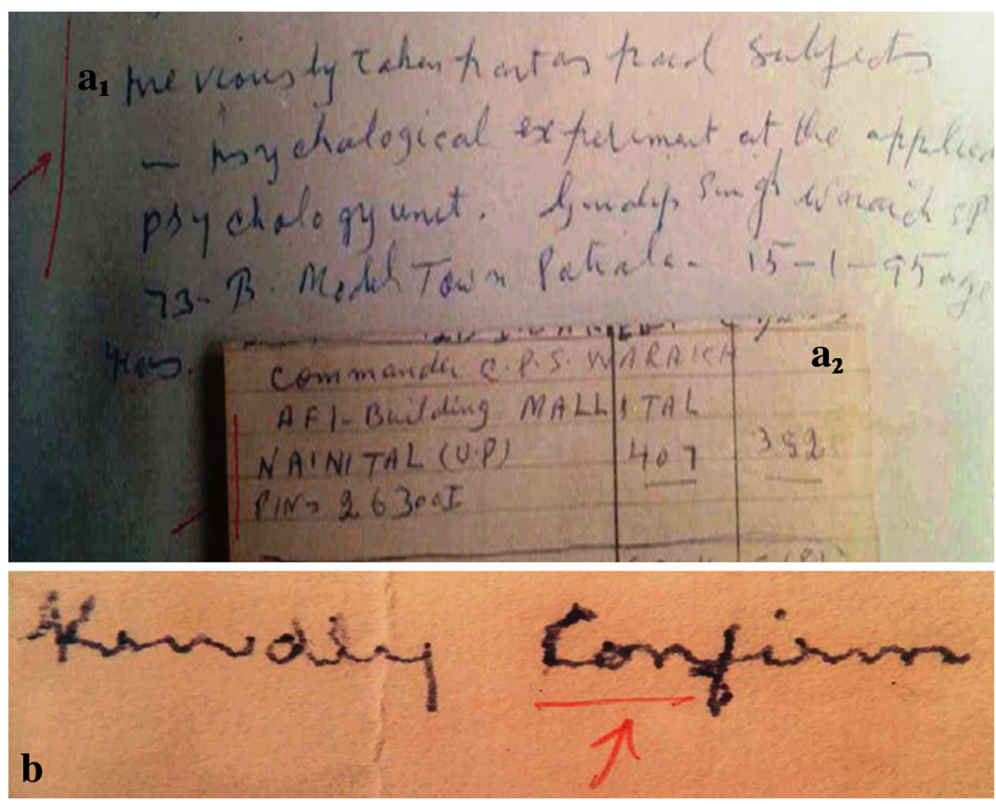

Fig. 5 Writing Speed. $\left(a_{1}\right)$ Handwriting sample of an aged individual showing decline in writing speed as compared to the handwriting sample executed before the age of 60 years $\left(a_{2}\right)$. (b) Handwriting sample of Parkinsonism patient showing very slow speed of writing 

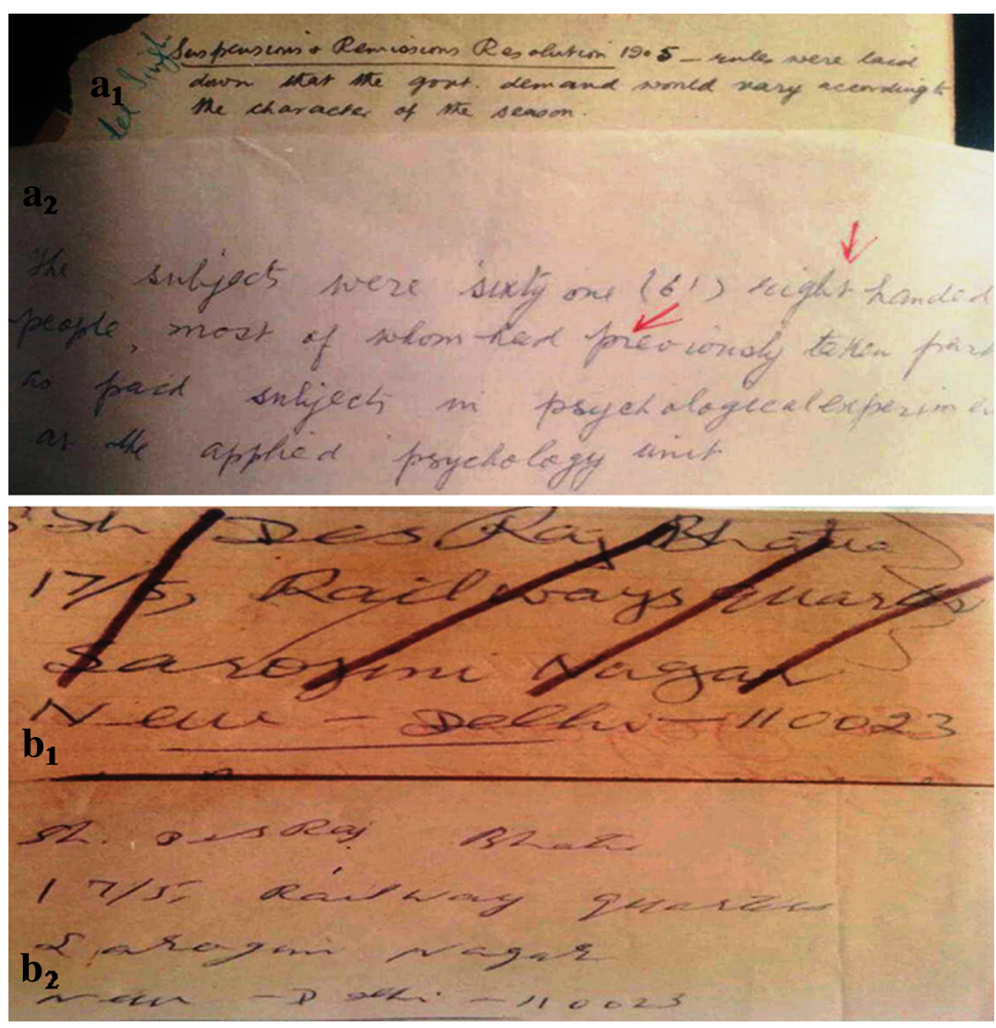

Fig. 6 Size of writing. $\left(a_{1}\right)$ Previous handwriting sample of an aged person executed before the age of 60 years. $\left(a_{2}\right)$ Handwriting sample of old aged subject revealing marked increase in size as compared to handwriting sample executed during earlier time period $\left(a_{1}\right)$. $\left(b_{1}\right)$ Previous handwriting sample of Parkinsonism patient before the onset of Parkinsonism. $\left(b_{2}\right)$ Handwriting sample of the same subject showing decrease in size of writing as compared to the earlier writing written during normal health conditions $\left(b_{1}\right)$

Paired $t$ test results of handwritings before and after onset of old age subjects (Table 3) revealed that old age significantly affects handwriting characteristics, such as tremor $(t=-11.809, p=.000)$, retouchings $(t=-4.149$, $p=.000)$, pen lifts $(t=-7.624, p=.000)$, letter formation $(t=-8.226, \quad p=.000), \quad$ abbreviation/simplification of letters $(t=-8.573, p=.000)$, initial and terminal strokes $(t=-12.522, p=.000)$, connecting strokes $(t=-6.244$, $p=.000)$, speed $(t=-10.254, p=.000)$, and overall size $(t=-7.000, p=.000)$. No significant change in alignment of writing has been observed under effect of old age $(t=-1.661, p=1.03)$.

Table 3 Paired samples $t$ test showing significance values in case of old age subjects

\begin{tabular}{|c|c|c|c|c|c|c|}
\hline \multicolumn{7}{|c|}{ Paired difference } \\
\hline Pair & Variables & Mean & Std. deviation & $t$ (test statistic) & $\begin{array}{l}\text { df } \\
\text { (degree of freedom) }\end{array}$ & Sig. (two-tailed) ( $p$ value \\
\hline Pair 1 & T_Bf-T_Af & -.74000 & .44309 & -11.809 & 49 & .000 \\
\hline Pair 2 & Rt_Bf-Rt_Af & -.26000 & .44309 & -4.149 & 49 & .000 \\
\hline Pair 3 & PL_Bf-PL_Af & -.58000 & .53795 & -7.624 & 49 & .000 \\
\hline Pair 4 & LF_Bf-LF_Af & -.58000 & .49857 & -8.226 & 49 & .000 \\
\hline Pair 5 & A/S_Bf-A/S_Af & -.60000 & .49487 & -8.573 & 49 & .000 \\
\hline Pair 6 & InT_Bf-InT_Af & -.80000 & .45175 & -12.522 & 49 & .000 \\
\hline Pair 7 & CS_Bf-CS_Af & -.48000 & .54361 & -6.244 & 49 & .000 \\
\hline Pair 8 & S_Bf-S_Af & -.72000 & .49652 & -10.254 & 49 & .000 \\
\hline Pair 9 & OS_Bf-OS_Af & -.50000 & .50508 & -7.000 & 49 & .000 \\
\hline Pair 10 & Al_Bf-Al_Af & -.08000 & .34047 & -1.661 & 49 & .103 \\
\hline
\end{tabular}

Table 3 shows paired samples $t$ test results in detail with means of difference of "Bf" and "Af," standard deviation values, significance values (two-tailed), $t$ values and degree of freedom obtained from analysis of handwriting characteristics in case of old age subjects 
Table 4 Paired samples $t$ test showing significance values in case of Parkinsonism subjects

\begin{tabular}{|c|c|c|c|c|c|c|}
\hline \multicolumn{7}{|c|}{ Paired difference } \\
\hline Pair & Variables & Mean & Std. deviation & $t$ (test statistic) & df (degree of freedom) & Sig. (two-tailed) ( $p$ value) \\
\hline Pair 1 & T_Bf-T_Af & -.72000 & .45826 & -7.856 & 24 & .000 \\
\hline Pair 2 & Rt_Bf-Rt_Af & -.20000 & .50000 & -2.000 & 24 & .057 \\
\hline Pair 3 & PL_Bf-PL_Af & -.76000 & .43589 & -8.718 & 24 & .000 \\
\hline Pair 4 & LF_Bf-LF_Af & -.68000 & .55678 & -6.107 & 24 & .000 \\
\hline Pair 5 & A/S_Bf-A/S_Af & -.80000 & .40825 & -9.798 & 24 & .000 \\
\hline Pair 6 & InT_Bf-InT_Af & -.76000 & .43589 & -8.718 & 24 & .000 \\
\hline Pair 7 & CS_Bf-CS_Af & -.80000 & .40825 & -9.798 & 24 & .000 \\
\hline Pair 8 & S_Bf-S_Af & -.68000 & .47610 & -7.141 & 24 & .000 \\
\hline Pair 9 & OS_Bf-OS_Af & -.72000 & .45826 & -7.856 & 24 & .000 \\
\hline Pair 10 & Al_Bf-Al_Af & -.12000 & .33166 & -1.809 & 24 & .083 \\
\hline
\end{tabular}

Table 4 shows paired samples $t$ test results in detail with means of difference of "Bf" and "Af," standard deviation values, significance values (two-tailed), $t$ values and degree of freedom obtained from analysis of handwriting characteristics in case of Parkinsonism subjects

Paired $t$ test results of handwritings before and after onset of Parkinsonism subjects (Table 4) revealed that Parkinsonism significantly affects handwriting characteristics, such as tremor $(t=-7.856, p=.000)$, pen lifts $(t=-8.718, p=.000)$, letter formation $(t=-6.107$, $p=.000)$, abbreviation/simplification of letters $(t=-9.798$, $p=.000)$, initial and terminal strokes $(t=-8.718, p=.000)$, connecting strokes $(t=-9.798, p=.000)$, speed $(t=-7.141$, $p=.000)$, and overall size $(t=-7.856, p=.000)$. No significant change in retouchings $(t=-2.000, p=.057)$ and alignment of writing has been observed under the effect of Parkinsonism $(t=-1.809, p=0.83)$.

\section{Discussion}

Presence of tremor in the affected writings as compared to their normal writings indicates overall inability of subjects to execute writings in a smooth manner (Smits et al. 2014; Walton 1997). It has been observed in some adjoining letters and smooth strokes at some places (Brewester 1932; Harrison 1966; Osborn 1929). This indicates a sudden loss of control of subjects over the pen and then improvement in writing ability intermittently. Despite these peculiarities found in writings of the old age persons and individuals suffering from Parkinsonism, it has been observed that particular type of tremors cannot be attributed solely to a particular type of neuromuscular factor (Brewester 1932).

In both cases of affected writings, retouching has been found to be of bold nature made in a careless manner, which indicates lack of any effort to join the strokes in a precise manner (Brewester 1932; Osborn 1929). Pen lifts have been found to be the prominent feature in both groups, and the writers did not attempt to rejoin the strokes in a careful manner (Brewester 1932; Harrison 1966; Hilton 1956, 1977; Osborn 1929; Walton 1997). Some individuals suffering from Parkinsonism have been found to write all letters separately.

In the case of individuals suffering from Parkinsonism, line quality of letters was found to be affected to a marked extent, and they showed the tendency to abbreviate letters or their parts (Walton 1997). This is due to the inability of the writers to form letters in a complex form. In the case of writings of old age persons, changes in writing ranged from the omission of diacritic marks and letters to the level of omission of even words. They did not make an attempt to complete the letters in such cases. Individuals suffering from Parkinsonism show reluctance in forming the letters in a complete form (Hilton 1977; Osborn 1929; Walton 1997). However, it has been observed that the writers in both cases showed the tendency to maintain the persistency of basic mode of production of the letters and individualized writing features, which might be helpful in formulating an opinion.

In writings of both old age persons and individuals suffering from Parkinsonism, there was a decline in the writing speed which ranged from a slight change in the fluency of letter formations to marked deterioration in muscular coordination resulting in a very slow writing speed (Smits et al. 2014). This gives a peculiar "on-off" feature to writing pressure (Walton 1997). Initial strokes in the writings of individuals suffering from Parkinsonism reveal difficulty faced by subjects in holding the pen at the beginning of writing. They were found to be using their second hand to hold the pen properly. Similar tremors and extra strokes have been observed in the terminal portions (Walton 1997). Alignment of the writing was not found to be significantly affected in the writings of both old age persons and individuals suffering from Parkinsonism. An increase in the size of writings was observed in a few writings of old age persons. Size of the letters in different signatures of the same writer was 
found to be inconsistent in the case of old age persons, that is, sudden changes in the size of letters even in the same word, which shows lack of control over the pen. Kinematic studies on the handwriting of old age persons also point toward disturbance in the overall size of their writing (Caligiuri et al. 2014; Drempt et al. 2011). A peculiar decrease in the overall size of writing (referred to as micrographia) has been observed in all the writing samples of individuals suffering from Parkinsonism (Boisseau et al. 1986; Harrison 1966; Osborn 1929; Storer 1970; Walton 1997). There are studies reporting the kinematic analysis of handwritings of individuals suffering from Parkinsonism, which indicate a decline in the size of writing strokes (Gemmert et al. 1999, 2001; Gemmert et al. 2003; Inzelberg et al. 2016; Kim et al. 2004; Rosenblum et al. 2013).

Paired $t$ test was performed to determine whether there would be a statistical significant difference in handwriting characteristics between paired observations ("Bf" and "Af"). The statistical results of old age and Parkinsonism subjects clearly depict $p<0.05$ in almost all handwriting characteristics. Thus null hypothesis is rejected in case of those characteristics. From the qualitative and statistical observation, it is suggested that old age and Parkinsonism affect most of the handwriting characteristics significantly.

\section{Conclusion}

This study demonstrates the fact that in cases of disputed handwriting/signatures involving old age persons and individuals suffering from Parkinsonism, there is a marked deterioration in the quality of writings, due to which the affected writings appear different altogether as compared to the corresponding normal writings.

Moreover, handwriting experts may face problems during comparison of the affected writings with those executed during normal health condition due to inadequate number of contemporaneous standard samples. Thus, it is a prerequisite for the experts to be well aware of the effects of old age and Parkinsonism on handwriting while handling such cases. This study has been conducted keeping all these facts in view. Results of this study should assist the forensic document experts while solving similar cases.

\section{Abbreviations}

Af: Handwriting samples obtained from subjects after the onset of old age and Parkinsonism; Bf: Handwriting samples obtained from subjects before the onset of old age and Parkinsonism

\section{Acknowledgements}

We wish to thank UGC (University Grants Commission), New Delhi (India) for providing fellowship to one of the authors under BSR (Basic Science Research) scheme in order to carry out the present research study. We also want to thank all the subjects who voluntarily participated in this study.

\section{Funding}

One of the authors is getting fellowship under BSR scheme by University Grants Commission, New Delhi (India).

\section{Availability of data and materials}

The raw data is available with the corresponding author, Dr. Komal Saini.

\section{Authors' contributions}

All the authors equally participated in formulation of this research paper. Both authors read and approved the final manuscript.

\section{Ethics approval and consent to participate}

Ethical approval to collect samples was granted by Institutional Ethical Committee, Punjabi University (Patiala) vide letter no. 282/DLS/HG, dated 20-02-2015.

\section{Consent for publication}

The subjects have been informed about the nature of study and handwriting samples have been collected along signed consent forms of subjects, stating "handwriting samples collected will be solely used for the purpose of research and shall not be misused".

\section{Competing interests}

The authors declare that they have no competing interests.

\section{Publisher's Note}

Springer Nature remains neutral with regard to jurisdictional claims in published maps and institutional affiliations.

Received: 8 January 2019 Accepted: 30 April 2019

Published online: 24 May 2019

\section{References}

Boisseau M, Chamberland G, Gauthier S (1986) Handwriting analysis of several extrapyramidal disorders. Presented at the annual meetings of C.S.F.S, Niagra Fall

Brewester F (1932) Contested documents and forgeries. The Book Company Ltd, Calcutta

Caligiuri MP, Kim C, Landy KM (2014) Kinematics of signature writing in healthy aging. J Forensic Sci 59(4):1020-1024

Drempt NV, McCluskey A, Lannin NA (2011) Handwriting in healthy people aged 65 years and over. Aust Occup Ther J 58:276-286

Gemmert AWAV, Alder CH, Stelmach GE (2003) Parkinson's disease patients undershoot target size in handwriting and similar tasks. J Neurol Neurosurg Psychiatry 74:1502-1508

Gemmert AWAV, Teulings HL, Stelmach GE (2001) Parkinsonian patients reduce their stroke size with increased processing demands. Brain Cogn 47:504-512

Gemmert AWAV, Teulings HL, Vidal JL, Stelmach GE (1999) Parkinson's disease and the control of size and speed in handwriting. Pergamon Neuropsychologia 37:685-694

Harralson HH (2013) Developments in handwriting and signature identification in the digital age. Elsevier, Anderson Publishers, UK

Harrison WR (1966) Suspect documents: their scientific examination, 5th edn. Sweet and Maxwell Ltd, U.K

Hilton O (1956) Influence of serious illness on handwriting identification. Postgrad Med 19(2):A-36-48

Hilton O (1977) Influence of age and illness on handwriting: identification problems. Forensic Sci 9(3):161-172

Huber RA, Headrick AM (1999) Handwriting identification: facts and fundamentals. CRC Press LLC, Florida, Boca Raton

Inzelberg R, Plotnik M, Harpaz NK, Flash T (2016) Micrographia, much beyond the writer's hand. Park Relat Disord 26:1-9

Kim EJ, Lee BH, Park KC, Lee WY, Na DL (2004) Micrographia on free writing versus copying tasks in idiopathic Parkinson's disease. Parkinsonism Relat Disord 11:57-63

Komal S (2015) A study of various factors influencing handwriting. Lambert Academic Publishing, Patiala

Nackaerts E, Broeder S, Pereira MP, Swinnen SP, Vandenberghe W, Nieuwboer A, Heremans E (2017) Handwriting training in Parkinson's disease: a trade-off between size, speed and fluency. PLoS One 12(12):e0190223

Osborn AS (1929) Questioned documents, 2nd edn. Boyd Publishing Co, Albany 
Rosenblum S, Samuel M, Zlotnik S, Erikh I, Schlesinger I (2013) Handwriting as an objective tool for Parkinson's disease diagnosis. J Neurol 260(9):235761. https://doi.org/10.1007/s00415-013-6996-x

Rosenblum S, Werner P (2006) Assessing the handwriting process in healthy elderly persons using a computerized system. Aging Clin Exp Res 18(5):433-439

Smits EJ, Tolonen AJ, Cluitmans L, Gils MV, Conway BA, Zietsma RC, Leenders KL, Maurits NM (2014) Standardized handwriting to assess bradykinesia, micrographia and tremor in Parkinson's disease. PLoS ONE 9(5):e97614

Storer WH (1970) The study of a Parkinsonian's signature writing prior to and following treatment with the drug L-Dopa. Presented at 22nd meeting of American Academy of Forensic Sciences

Sulner HF (1966) Disputed documents. Oeana Publications Inc, New York

Walton J (1997) Handwriting changes due to aging and Parkinson's syndrome. Forensic Sci Int 88:197-214

\section{Submit your manuscript to a SpringerOpen ${ }^{\circ}$ journal and benefit from:}

- Convenient online submission

- Rigorous peer review

- Open access: articles freely available online

High visibility within the field

- Retaining the copyright to your article

Submit your next manuscript at $\boldsymbol{\nabla}$ springeropen.com 